\title{
LONG SURVIVAL OF STALK PIECES OF METACRINUS ROTUNDUS CARPENTER, A MODERN STALKED CRINOID, IN AN AQUARIUM
}

OJI, Tatsuo*, Geological Institute, University of Tokyo, Tokyo 113, Japan; AMEMIYA, Shonan, Misaki Marine Biological Station, University of Tokyo, Miura 283-02, Japan

Previous underwater observations have demonstrated that detached stalk pieces with a few noditaxes are often found in the habitats of modern isocrinid crinoids. They sometimes stand on the substrate by grasping hard objects by cirri. According to the growth of the stalk, the distal parts are repeatedly detached from the main body and discarded on the sea floor. There has been no information about the "fate" of such isolated stalk pieces. Abundance of stalk pieces of crinoids in the geologic column must be considered with reference to the modern analogue.

We have collected by dredging specimens of modern stalked crinoid Metacrinus rotundus Carpenter from the depths of $135-150 \mathrm{~m}$ in Suruga Bay, central Japan. Specimens were transferred to a large temperature controlled aquarium $\left(13^{\circ} \mathrm{C}\right)$ within several hours after capture. While keeping the animals, a few specimens have autotomized the distal stalk, and isolated pieces with a few noditaxes were left in the aquarium. They have kept the same postures and still attached to pebbles by cirri for approximately one year. No further disarticulation nor regeneration occurred to the stalk pieces.

Section of the stalk piece stained by hematocyanin showed that the nuclei were well colored and the fragmental stalk was considered as living. This result strongly suggests a possibility that such fragmental stalks can live for a long time in the natural environment. Abundant occurrence of stalk elements from the geologic record have been attributed to a taphonomic process; selective accumulation of a part of the body after death, but the present results imply that these stalk pieces could live alone for a long time on the sea floor. 